\title{
UNA DEMOCRACIA NADA PERFECTA: CONTINUIDADES EN LA FINANCIACIÓN DE LOS PARTIDOS ESPAÑOLES DESDE LA TRANSICIÓN POLÍTICA A NUESTROS DÍAS
}

\author{
Far from a perfect democracy: continuities in the funding of Spanish political \\ parties since the political transition to democracy to the present.
}

\author{
Manuel Maroto Calatayud \\ Universidad de Castilla-La Mancha \\ manuel.maroto@uclm.es
}

Recibido: 05-09-2017 - Aceptado: 19-12-2017

\begin{tabular}{|c|c|}
\hline $\begin{array}{l}\text { Cómo citar este artículo/Citation: } \\
\text { Manuel Maroto Calatayud (2018), “Una democracia nada } \\
\text { perfecta:continuidades en la financiación de los partidos } \\
\text { españoles desde la transición política a nuestros días”, Hispania } \\
\text { Nova, 16, págs. 685-711, DOI: https://doi.org/10.20318/ } \\
\text { hn.2018.4052 }\end{array}$ & $\begin{array}{l}\text { Copyright: C HISPANIA NOVA es una revista debidamente } \\
\text { registrada, con ISSN } 1138-7319 \text { y Depósito Legal M 9472-1998. } \\
\text { Los textos publicados en esta revista están -si no se indica lo } \\
\text { contrario- bajo una licencia Reconocimiento-Sin obras derivadas } \\
\text { 3.0 España de Creative Commons. Puede copiarlos, distribuirlos } \\
\text { y comunicarlos públicamente siempre que cite su autor y la } \\
\text { revista y la institución que los publica y no haga con ellos obras } \\
\text { derivadas. La licencia completa se puede consultar en: } \\
\text { http://creativecommons.org/licenses/by-nd/3.0/es/deed.es }\end{array}$ \\
\hline
\end{tabular}

Resumen: En este artículo vamos a realizar un pequeño recorrido por la financiación ilegal de partidos políticos en España desde la transición política. Aunque nos vamos a centrar en la primera de ellas, se trata en realidad de dos historias, entremezcladas: la primera es la de la "financiación" de los partidos españoles desde la democracia, lo que sus prácticas y dinámicas financieras cuentan acerca de estas formaciones y, en general, acerca del sistema español de partidos. La segunda, la historia de lo "ilegal" en materia de financiación de partidos: cómo las élites políticas han reaccionado a los escándalos, y dónde han ido poniendo la línea divisoria entre lo legítimo y lo ilegítimo. Ambas retratan una democracia nada perfecta: una que, de hecho, a menudo aparenta no tener aspiraciones de perfeccionarse, sino más bien de perseverar en una cultura organizativa y partidista con fuertes anclajes en las deficiencias del sistema de partidos surgido de la transición política.

Palabras clave: Financiación ilegal de partidos políticos, corrupción, transición política, cultura política, modelos de partido, democracia interna.

\begin{abstract}
This paper analyzes the practices of illegal funding of political parties in Spain since the transition to democracy. It involves two different interrelated narrations: the first one has to do with the "funding" of Spanish parties, with how their financial practices and dynamics tells us about some particularities of these political organizations and the Spanish party system. The second narration addresses the history of what is "illegal" regarding political party funding: how political elites have reacted to scandals, and how the line separating legitimate and illegitimate funding practices has evolved. Both approaches describe a far from perfect party democracy: one that, in fact, often seems not to aspire to improvement, but rather to perseverate in organizational party cultures that are strongly rooted in the deficiencies of the party system emerged from the Spanish political transition to democracy.
\end{abstract}

Keywords: Illegal funding of political parties, corruption, Spanish political transition, political culture, political party models, internal democracy 


\section{Introducción}

Cuando en España se habla de financiación ilegal de partidos (sobra decir que se habla mucho de ella) ${ }^{1}$ suele hacerse desde una de las dos perspectivas que esbozamos a continuación. Ambas constituyen, sin duda, componentes relevantes del fenómeno; cada una de las dos arrastra, además, sus propias limitaciones.

Para una primera aproximación, la financiación ilegal de partidos es fundamentalmente un problema de confianza pública en las instituciones. La corrupción produce desconfianza en el sistema político, y es el detonante de procesos de deslegitimación de instituciones y personalidades políticas. Esos procesos tienen diversos efectos sociológicos e institucionales, de los cuales, los que suelen recabar la mayor atención son los efectos electorales o, en su caso, la -siempre llamativaaparente ausencia de los mismos ${ }^{2}$. Esta forma de pensar la financiación ilegal de partidos gira en torno a una concepción electoral de la política, y se trata de un discurso apegado a los vaivenes de la opinión pública. Con cierta frecuencia esta aproximación suele obviar los aspectos históricos, culturales, económicos, políticos y jurídicos del problema de la financiación de partidos; es la actitud que, en una de sus formas más desnudas, ha estado históricamente presente en el legislador español (recordemos, los propios partidos) a la hora de enfrentarse al problema a través de reformas legales y administrativas.

Para una segunda aproximación, más plural e interesante, la financiación ilegal es un mecanismo de distorsión y captura de las instituciones políticas, administrativas y económicas. A través de la corrupción, y en particular de la financiación de partidos, se gobierna puenteando las instituciones democráticas (discurso democrático), se

\footnotetext{
${ }^{1}$ Ver J. M. FERNÁNDEZ CALLEJA, "La crisis económica y los escándalos de corrupción aumentan la audiencia de los debates televisivos", Opción, n. 11 v. 32, 2016

${ }^{2}$ M. CAÍNZOS y F. JIMÉNEZ, "El impacto de los escándalos de corrupción sobre el voto en las elecciones generales de 1996", Historia y política, n. 4, 2000; B. BARREIRO, e I. SÁNCHEZ CUENCA, "Las consecuencias electorales de la corrupción", Historia y política, n. 4, 2000; M. VILLORIA y F. JIMÉNEZ, "La corrupción en España (2004-2010): datos, percepción y efectos", Revista Española de Investigaciones Sociológicas, n. 1 v. 138, 2012
} 
distorsiona el funcionamiento de la administración y del orden socioeconómico (discurso jurídico), y se altera la libre competencia en los mercados (discurso de mercado). En términos políticos, esta aproximación está presente en diferentes espectros ideológicos y en una diversidad de actores con motivaciones distintas y a veces en conflicto. Si la primera aproximación presenta cierta tendencia a reducir el problema a uno que encaje en lo opinológico, estos discursos tienden a obviar, también, amplias esferas del problema: en particular, subrayaremos aquí, los relativos a la cultura política, los efectos de la corrupción sobre el funcionamiento del sistema de partidos español, y la relación con la sempiterna cuestión de la democracia interna de las organizaciones políticas con las prácticas de financiación. En alguna de sus variantes se percibe también una tendencia a la simplificación conspirativa de relaciones que en realidad son más complejas y dependientes de inercias históricas y del contexto sociológico y político que una simple compraventa de la política.

Como un problema añadido, a ambas concepciones les es común una comprensión casuística: el problema de la financiación ilegal de partidos es tratado como una sucesión de casos y de escándalos, no del todo conectados entre sí. Sin duda esto tiene que ver con cuáles son las dos vías por las que la financiación ilegal llega al debate público: los procesos judiciales y la información periodística. La comprensión en formato de casos tiende, también, a obviar las continuidades y los contextos, a dibujar tramas corruptas como episodios de desviación de la norma y como rituales de caída y expiación en el plano de la ética política. Contra esta tónica general, existe una necesidad de innovar en las formas de narrar el problema de la financiación de los partidos en nuestro país, de crear nuevas maneras de comprender la corrupción e intervenir en la materia ${ }^{3}$.

En este sentido, la narración que vamos a hacer aquí de la financiación ilegal de partidos en la democracia española no es cronológica, y menos aún exhaustiva; por el

\footnotetext{
${ }^{3}$ Pensemos, por ejemplo, en la idea, tan americana, de que el dinero habla: si la información financiera de los partidos españoles reflejara realmente su actividad real y fueran accesibles al público (no en la versión claramente limitada que conocemos a través de los informes anuales del Tribunal de Cuentas), de ellos podríamos obtener una historia distinta de nuestros partidos. Ni siquiera los datos disponibles se publican en formatos reutilizables; tuvo que ser el colectivo cuentasclaras.net el que hace unos años volcara en una plataforma de visualización los informes del Tribunal de Cuentas 2009-2011. Recuperado de: https://public.tableau.com/profile/fontanon\#!/vizhome/FinanciacindePartidosPolticos2009-2011v2/
} 
contrario, lo que se busca es subrayar algunas formas de pensar el problema a menudo infrarrepresentadas en la discusión respecto al mismo ${ }^{4}$. Queremos ilustrar, aunque sea tangencialmente, una cuestión: la de la influencia de las prácticas de financiación sobre la formación y consolidación de los modelos organizativos de los partidos españoles. En definitiva, la cuestión de cómo el dinero, entendido como la abstracción de interacciones sociales, ha contribuido a formar la actual cultura política y organizativa en estas organizaciones.

\section{El sistema español de partidos: un modelo post-watergate}

Es casi un lugar común afirmar que la corrupción es una constante en la historia política, y efectivamente distintos autores ${ }^{5}$ han trazado la evolución de este tipo de prácticas hasta tiempos muy lejanos al nuestro. La historia de cómo la financiación ilegal de partidos ha pasado a tener la importancia actual es más corta, siquiera porque los partidos políticos son instituciones relativamente recientes, hijas de la modernidad política. Para abordar el papel de la financiación de las formaciones políticas en el caso español es útil tener presente, en primer lugar, el momento histórico en que surge el sistema español de partidos. Los años setenta fueron, en efecto, una época de transformación internacional de las concepciones de la corrupción y del significado de la ética en las democracias liberales, cambios que tuvieron uno de sus motores principales en los Estados Unidos, y que han de entenderse en el contexto de tensión con la Unión Soviética. Los setenta en EEUU fueron los años de Watergate y Lockheed, de la aprobación de lo que todavía es la base de la legislación de la materia en financiación de campañas americana (la Federal Election Campaign Act de 1971, reformada en 1974 y 1976) y de la seminal sentencia Buckley vs. Valeo (1976), sobre financiación de campañas. Una época que respondía a un nuevo contexto social, el de

\footnotetext{
${ }^{4}$ Algo que tienen en común esas formas de pensar es la utilidad de un enfoque historiográfico, en un sentido amplio; el monográfico que recoge este mismo artículo ejemplifica, efectivamente, la necesidad y la oportunidad de enriquecer con una comprensión histórica una discusión a menudo dominada por juristas y economistas, la sociología de la opinión pública, y por el enfoque periodístico.

${ }^{5}$ J. T. NOONAN, Bribes: The intellectual history of a moral idea, The University of California Press and Macmillan Publishing Company, 1984; C. A. BRIOSCHI, Breve historia de la corrupción, de la antigüedad a nuestros días, Ed. Taurus, 2010; B. BUCHAN, y L. HILL, An intellectual history of political corruption. Springer, 2014
} 
la desaparición del welfarismo del New Deal, la emergencia del neoliberalismo, y con ella de una nueva relación con la política. A modo de ejemplo, la confianza en el gobierno federal estadounidense alcanzó su pico en 1964 (el 77\% de los americanos creía entonces que el gobierno hacía lo correcto en la mayor parte de las ocasiones), y empieza a partir de ese año a caer de forma casi ininterrumpida hasta alcanzar un $19 \%$ en $2015^{6}$. La guerra de Vietnam, el escándalo Watergate y la lucha por los derechos civiles fueron los detonantes más visibles de ese cambio social. Una época, además, en la que a las élites políticas americanas les preocupaba que la corrupción se percibiera como una característica inherente al capitalismo, favoreciendo la simpatía hacia el comunismo.

Nos interesa contextualizar el caso español en el marco internacional por dos motivos en especial. El primero es bastante obvio: es precisamente durante estos años de Guerra Fría y de intensificación del conflicto político y cultural entre bloques cuando se empieza a formar lo que sería el sistema español de partidos. Ello supuso toda una serie de condicionantes y tutelas, por lo demás bien retratadas en los relatos menos edulcorados de la transición política española ${ }^{7}$.

El segundo resulta un poco más complejo, y tiene que ver con el papel de Estados Unidos en la formación del que sin duda es uno de los discursos anticorrupción más prevalentes hasta la actualidad: el enarbolado por las instituciones internacionales, y en particular por las instituciones financieras internacionales (Banco Mundial, Fondo Monetario Internacional), pero también por organizaciones supranacionales como la Unión Europea. Este discurso, que fundamentalmente entiende la corrupción como un problema económico (la corrupción perjudica el comercio internacional, la libre competencia y el crecimiento), emerge súbitamente en los años noventa, de tal forma que en un periodo de apenas diez años (1994-2003) casi todas las principales organizaciones supranacionales, desde la ONU a la UE, la OCDE y el Consejo de Europa, habían promovido sus propios convenios

6 PEW RESEARCH (2015), Trust in government: 1958-2016, recuperado de http://www.peoplepress.org/2015/11/23/1-trust-in-government-1958-2015/, 25/11/2015, consultado el: 10/09/2017

${ }^{7}$ Por ejemplo: J. E. GARCÉS, Soberanos e intervenidos, estrategias globales, americanos y españoles. Siglo XXI de España Editores, 2008 
internacionales contra corrupción. Esa extraordinaria emergencia de la preocupación por la corrupción nos conecta de nuevo con los convulsos años setenta en Estados Unidos: en particular, con la aprobación de la Foreign Corrupt Practices Act en 1977, ley que, como reacción a Watergate, prohibía a las empresas americanas pagar sobornos a funcionarios o candidatos políticos extranjeros. Desde entonces, para EEUU fue un interés constante nivelar el terreno de juego, por la vía de promover normas internacionales que prohibieran prácticas similares a otros países, de tal forma que las empresas americanas no estuvieran, al menos sobre papel, en desventaja competitiva. Con todo, no lo consiguió hasta la caída del bloque soviético, cuando la posibilidad de expansión económica hacia el bloque socialista y el nuevo fervor globalizador representaban una oportunidad inigualable para evitar a las potencias occidentales aranceles y barreras innecesarias, incluida la corrupción que era entendida como tal, en el avance hacia las economías del Este.

Hay que destacar, por último, que la gran mayoría de estos instrumentos internacionales se centraron en la corrupción como un problema relativo a las transacciones económicas internacionales, no como un problema de institucionalidad democrática ni relativo a la necesidad de avanzar en los mecanismos de representación política de las democracias liberales ante una creciente desafección hacia las mismas. Eso dejó la cuestión de la financiación de los partidos políticos fuera de la normativa y de la presión internacional, quedando relegada a ser una materia interna, y en la práctica excluida del discurso dominante sobre la corrupción. De hecho, EE. UU. se opuso, por ejemplo, a que la Convención de Naciones Unidas contra la Corrupción de 2003 entrara a regular la financiación de partidos y campañas, algo que sí habían propuesto otros países. En el plano internacional, tan solo el Consejo de Europa, y en particular el Grupo de Estados contra la Corrupción (GRECO) que funciona en su seno, ha mostrado una preocupación por la corrupción que abarque la financiación de partidos desde una óptica que vaya más allá de una concepción apegada a los mercados internacionales.

Eso explica, siquiera parcialmente, que la corrupción de funcionarios extranjeros en las transacciones económicas internacionales fuera introducida en el Código Penal español como delito específico en 2003, pero que la financiación ilegal de partidos, una 
conducta que, sin duda alguna, había generado muchísima más alarma social en nuestro país desde décadas atrás, solo fuera tipificada en 2015, de manera muy defectuosa, tras años de críticas a España por parte del GRECO ${ }^{8}$. Con esta breve contextualización internacional avanzamos el siguiente epígrafe, sobre las prácticas de financiación de los partidos españoles desde la formación del sistema de partidos.

\section{La financiación de los partidos españoles: continuidades desde la transición política a nuestros días}

La transición política española implicó la puesta en marcha de un sistema de partidos "homologable" al de otros países europeos en un lapso reducido de tiempo, en un proceso acelerado de formación organizativa que en otros países había llevado décadas. Es en el ocaso de cuarenta años de dictadura franquista, que había erradicado con la mayor saña los partidos republicanos, cuando surgen las nuevas formaciones de entre las élites franquistas (UCD, AP), se relanzan otros partidos casi olvidados (PSOE) y las pocas organizaciones que sobrevivieron a los años de actividad en la clandestinidad (el PCE) tienen que adaptarse a un contexto totalmente distinto. Esta transición se producía, precisamente, en un momento de crisis a nivel internacional de los partidos políticos como organizaciones de masas, y en una reconfiguración de las formas de organización política hacia modelos profesionalizados, de menor carga ideológica, y más volcados hacia los mecanismos de captación del votante a través de los medios de comunicación, y hacia la explotación de los recursos que aporta la cercanía al Estado y a las empresas, que a la creación de redes de colaboración y actividad política de base. Era, en definitiva, el momento de lo que la sociología política llamó el "partido catch-all", tal y como lo describió Otto Kirchheimer". La frase atribuida a Alfonso Guerra en 1979, "prefiero diez

\footnotetext{
${ }^{8}$ La tercera ronda de evaluación del GRECO, sobre financiación de partidos y control penal de la corrupción, comenzó en 2007 y constituye una importante fuente de información comparativa sobre la regulación del dinero en política. Los informes están disponibles en: http://www.coe.int/en/web/greco/evaluations/round-3

${ }^{9}$ O. KIRCHHEIMER, "El camino hacia el partido de todo el mundo", en K. LENK y F. NEUMANN (eds.), Teoría y sociología críticas de los partidos políticos, Anagrama, 1980
} 
minutos en televisión a diez mil militantes"10, sintetiza la nueva tónica de los tiempos, una en la que los recursos y el acceso a financiación y a los medios de comunicación daría la victoria política. En términos económicos, las formas de movilización capitalintensivas (la financiación a través de fuentes diversas) desplazaban a las trabajointensivas (la militancia, el trabajo voluntario, las redes de solidaridad, etc.) que una vez fueron parte fundamental de la labor de los partidos políticos, al menos de los que seguían el modelo organizativo del partido de masas obrero. El dinero cobraba así un nuevo protagonismo en una política concebida como una contienda electoral con un coste cada vez mayor.

Resulta llamativo constatar hasta qué punto las inercias relativas a la financiación de partidos que arraigaron durante los años de la transición política española permanecieron en el tiempo, hasta el punto en que todavía perviven, más o menos adaptadas, en la actualidad. El análisis de la sucesión de escándalos y de casos de financiación ilegal revela, efectivamente, dinámicas muy similares durante todos los años de democracia. No vamos aquí a insistir en la crónica y enumeración de esos casos, que puede encontrarse realizada en investigaciones periodísticas y en procedimientos judiciales de manera relativamente temprana, en particular desde finales de los años ochenta y durante los convulsos noventa ${ }^{11}$, y que ha conocido un interesante resurgir en los últimos años, a raíz fundamentalmente del escándalo Gürtel y Bárcenas ${ }^{12}$. Sí que queremos poner la atención en la pervivencia de continuidades y dinámicas que subyacen a todos ellos, tan fáciles de adivinar como, a veces, difíciles de aislar entre el aluvión de datos, sumarios interminables, intrigas políticas e historias personales e institucionales.

\footnotetext{
${ }^{10}$ P. J. RAMÍREZ, Así se ganaron las elecciones 1979, Prensa Española, 1979

${ }^{11}$ C. DÁVILA y L. HERRERO, De Fraga a Fraga: crónica secreta de Alianza Popular, Plaza y Janés, 1989; J. DÍAZ HERRERA y R. TIJERAS, El dinero del poder, Plaza y Janés, 1991; J. L. GALIACHO y C. BERBELL, FILESA: Las tramas del dinero negro en la política, Temas de Hoy, 1995; M. SÁNCHEZ SOLER, Negocios privados con dinero público: el vademécum de la corrupción de los políticos españoles, Foca, 2003

${ }^{12}$ E. EKAIZER, El caso Bárcenas, Planeta, 2013; M. MAROTO CALATAYUD, La financiación ilegal de partidos políticos: un análisis político-criminal, Marcial Pons, 2015; E. EKAIZER, Queríamos tanto a Luis, Temas de Hoy, 2015; B. GARZÓN, El fango: cuarenta años de corrupción en España, Debate, 2015; M. GALLERO, Bárcenas. La caja fuerte: Los papeles secretos del tesorero del PP, La esfera de los libros, 2016
} 
Explicar el fenómeno de la corrupción en la financiación de partidos como el resultado, en buena medida, de la forma en que surgió el sistema español de partidos dista mucho de ser un recurso literario. El 1 de julio de 1976, cuando Arias Navarro anuncia su dimisión como presidente del gobierno, Manuel Fraga, entonces vicepresidente del Gobierno y ministro de la Gobernación, realizaba una entrevista con la periodista Pilar Urbano. La dimisión señalaba que urgía acelerar el proceso de constitución de los nuevos partidos, entre los que se incluía el promovido por el propio Manuel Fraga. La periodista pregunta "¿cómo se financiarán los partidos políticos? Se teme que, de no apoyar fuertemente el Estado, haya que recurrir a las multinacionales o al capitalismo nativo". La respuesta resulta significativa, leída hoy: "no hay tema más difícil, ni más oscuro, en la mayoría de los países" que la financiación de los partidos políticos. "Creo que la solución que da la Ley de Asociaciones es prudente y realista. Dejemos que el tiempo y la costumbre la apliquen correctamente" ${ }^{13}$. Lo cierto es que toda la década siguiente (la primera Ley de Financiación de Partidos no es aprobada hasta 1987) fue una época de experimentación en modelos de financiación política en la que apenas hubo frenos éticos o legales. Una situación percibida como "salvaje oeste" o de "guerra total" (en palabras del entonces dirigente de Alianza Popular Jorge Verstrynge $\left.{ }^{14}\right)$. El modelo español de financiación de partidos, retomando las palabras de la entrevista, tuvo de todo de aquello desde el principio: desde luego el fuerte apoyo del Estado, y también el recurso a multinacionales y al "capitalismo nativo". Todo ello se dejó, efectivamente, al tiempo y a la costumbre, y tanto fue el tiempo y tanta la tolerancia con las viejas y nuevas costumbres, que se permitió cristalizar una cultura política, con raíces en la masiva corrupción franquista, que todavía atraviesa el país. "La acumulación primitiva de la riqueza llevada a cabo mediante la corrupción durante el franquismo" quedaría así "no sólo condonada sino también santificada por el sistema democrático" 15 .

\footnotetext{
${ }^{13}$ M. GALLERO, Bárcenas. La caja fuerte, op. cit., pág. 90

${ }^{14}$ Ibídem, pág. 96

15 J. PRADERA, Corrupción y política: los costes de la democracia, Galaxia Gutenberg, 2014, pág. 19
} 


\section{El fuerte apoyo estatal}

El modelo de financiación pública consagrado preconstitucionalmente en la Ley de Asociaciones Políticas de 1976 y, sobre todo, en la también preconstitucional Ley de Partidos de 1978, ha perdurado en el tiempo sin apenas cuestionamiento ${ }^{16}$. La financiación pública de los partidos españoles ha sido generosa, y ha ido además generando nuevas fuentes de financiación pública: a la asignación con cargo a los presupuestos generales del Estado se ha ido progresivamente sumando la de los grupos parlamentarios y asambleas autonómicas, las comunidades autónomas y las entidades locales, así como otras vías indirectas como las subvenciones para gastos de seguridad y las deducciones fiscales otorgadas a las cuotas y donaciones partidistas. A todo eso hay que sumar las distintas provisiones para financiar la actividad electoral de los partidos, reguladas en la Ley Orgánica del Régimen Electoral General de 1985, y la financiación pública que también reciben las fundaciones políticas asociadas a los partidos. La evolución de las fuentes de financiación pública, particularmente de la financiación de sus actividades ordinarias no electorales, ha sido un proceso a medio camino entre la costumbre y la posterior legalización por vía de la reforma de la Ley de Financiación de Partidos Políticos de 1987, donde ha ido ganando especial peso la financiación local y autonómica.

Tan solo la reforma de esta ley en 2012, en el contexto del austeritarismo reinante durante la crisis, introdujo recortes en la cantidad asignada con cargo a los presupuestos generales, no $\sin$ abrir de manera solapada la vía a otras formas compensatorias de obtener ingresos (en concreto, la eliminación de los topes a las donaciones a las fundaciones políticas, operada a través de esa reforma). Los sucesivos cambios legales, lejos de problematizar esta cuestión, han mantenido, si no fortalecido, la dependencia de los partidos de las fuentes de financiación pública ${ }^{17}$,

\footnotetext{
${ }^{16}$ Algo que sí ha ocurrido en países como Italia, donde un referéndum en 1993 manifestó un 90\% de apoyo a eliminar esa fuente de financiación, pese a lo cual no ha sido eliminada hasta 2013.

${ }^{17}$ E. GARCÍA VIÑUELA y C. GONZÁLEZ DE AGUILAR, "Financiación de los partidos y búsqueda de rentas: un análisis de las reformas de la financiación política española de 2007 y 2012", Revista Española de Ciencia Política, n. 34, 2014, pág. 149; J. RODRÍGUEZ TERUEL y F. CASAL BERTOA, "La financiación pública de los partidos políticos: España en perspectiva comparada". Presupuesto y Gasto Público, n. 82, 2016, pp. 165-166; J. RODRIGUEZ TERUEL, "Dinero público y ciudadanos ausentes: La
} 
manteniéndose el porcentaje de financiación privada declarada (cuotas, donaciones) en cifras muy bajas, una constante desde la transición política. El último informe publicado por el Tribunal de Cuentas en enero de 2017, relativo al ejercicio 2013, revela que los partidos recibieron ese año casi 217 millones de euros en subvenciones públicas, mientras que su financiación privada ascendió a 70,4 millones, de los cuales algo menos de 6 millones correspondían a cuotas, aportaciones y donaciones: el $2 \%$ de la financiación total declarada sigue constituyendo un porcentaje "de risa", como ya lo calificaban en los años de la transición algunos los dirigentes de los principales partidos ${ }^{18}$. El endeudamiento bancario total de los partidos, por su parte, ascendía ese año a 206 millones de euros ${ }^{19}$. El "fuerte apoyo del Estado" ha estado presente todos estos años sin que sin embargo sirviera de freno a la recepción de fondos por parte del capital privado nacional y extranjero.

\section{El capital extranjero}

A falta de base social en el país, de tiempo y también de intención alguna de favorecerla ${ }^{20}$, la financiación de los partidos españoles fue en su origen un proceso internacionalizado, donde se mezclaron contribuciones de partidos aliados (las ramas internacionales de distintos partidos políticos), de distintos gobiernos extranjeros (Estados Unidos, la URSS, etc.), empresas multinacionales (fue el caso de Flick en los

financiación de los partidos políticos en España", en F. J. LLERA RAMO, Desafección política y regeneración democrática en la España actual: diagnósticos y propuestas, Dykinson, 2016

${ }^{18}$ C. DÁVILA y L. HERRERO, De Fraga a Fraga... op. cit., pág. 109.

${ }^{19}$ TRIBUNAL DE CUENTAS, Informe de Fiscalización de los estados contables de los partidos políticos $y$ de las aportaciones percibidas por las fundaciones y asociaciones vinculadas, ejercicio 2013, recuperado en: https://www.boe.es/diario boe/txt.php?id=BOE-A-2017-3840, 09/02/2017, fecha de acceso: 10/09/2017, pp. 21-24.

${ }^{20}$ El temprano y continuado recurso a la financiación estatal de los partidos tiene una lectura clara desde las críticas a la transición política como un proceso de "desencanto programado", por el cual "la reinstauración del parlamentarismo y del sistema de partidos aparecieron ante las masas populares más oprimidas y/o radicalizadas como un fenómeno íntimamente unido al proceso de exclusión y sustitución de los movimientos de base por la circulación y los pactos de poder entre las élites" (ver. A. ORTI, "Transición postfranquista a la Monarquía parlamentaria y relaciones de clase: del desencanto programado a la socialtecnocracia transnacional", Política y sociedad, n. 7, v. 2, 1989: 17). En un sentido similar, según Pradera (J. PRADERA, Corrupción y política... op. cit., pág. 13) "los problemas de la corrupción y la tendencia de los políticos a afirmar su autonomía respecto a la sociedad y la baja participación son una doble y desdichada herencia del tardofranquismo y de la transición a la democracia, dos periodos dominados por el propósito de conseguir la desmovilización política: la irregular participación electoral, la debilidad del asociacionismo y la escasa militancia sindical y política so manifestaciones de ese mismo fenómeno". 
80, que afectó particularmente al PSOE pero en el que estuvieron implicados más partidos; más tarde fue también el caso, por ejemplo de Siemens, que pagó alrededor de 6 millones de euros a empresas vinculadas al PSOE como comisiones por la adjudicación de contratas del tren de alta velocidad Madrid-Sevilla). Algunos casos están históricamente bien documentados, como es el del PSOE y las ayudas recibidas por fundaciones políticas alemanas ${ }^{21}$. La Fundación Friedrich Ebert canalizó cuantiosas donaciones del consorcio industrial Flick (de tan infausto pasado que su fundador fue condenado en uno de los tres juicios a industriales alemanes en Nuremberg) al partido socialista, donaciones motivadas en la intención de frenar el avance del comunismo en España, interés que compartía también el gobierno estadounidense y otros aliados atlantistas ${ }^{22}$. Según distintas fuentes, AP y UCD también habrían recibido "dinero Flick" ${ }^{23}$, y facturado profusamente a fundaciones alemanas que canalizaban dinero proveniente de empresas multinacionales y fondos

${ }^{21}$ B. VARGAS, "Las relaciones entre el PSOE y la Fundación Friedrich Ebert durante el franquismo. 1967-1970", Hispania Nova. Revista de historia contemporánea, n. 4, 2004; A. MUÑOZ SÁNCHEZ, "La Fundación Friedrich Ebert y el socialismo español durante la transición a la democracia" en L. D. GÓMEZ ESCALONILLA, R. MARTÍN DE LA GUARDIA, R. PARDO SANZ (coords.), La apertura internacional de España: entre el franquismo y la democracia, 1953-1986, Sílex, 2016

\begin{abstract}
${ }^{22}$ A. SCHIFFRIN, Una educación política. Entre Paris y Nueva York, Península, 2001, pág. 205: "Más importante era el hecho de la financiación de partidos políticos extranjeros, una práctica que había cundido en la Europa de posguerra, que yo había apreciado ya en Inglaterra, y que continuaba ahora a ritmo acelerado. Para dar un ejemplo: nosotros estábamos de vacaciones en España en 1977 cuando, por primera vez desde Franco, el Partido Socialista presentaba un candidato en las elecciones parlamentarias. Me desconcertó el inmenso número de carteles que aparecían incluso en la pequeña población en la que estábamos instalados. ¿Cómo podía aquel partido recién legalizado disponer de tanto dinero? Más tarde Henry Kissinger se ufanaría en sus memorias de cómo los Estados Unidos habían canalizado fondos secretos a través del partido Socialdemócrata alemán para influir en los partidos socialistas español y portugués. Unos cuantos años después publiqué un libro de Willy Brandt, el dirigente socialista alemán y, en una cena en nuestra casa, decidió que sería buena ocasión para comprobar la veracidad del comentario de Kissinger. 'Típico de Henry -dijo Brandt riéndose-. Fue idea nuestra, pero él se ha llevado el mérito'. Lo que presumiblemente se había iniciado como solidaridad del Partido Socialista alemán con el español prohibido (el PSOE), se convirtió gradualmente en parte efectiva de la política exterior de Estados Unidos. El socialista Felipe González fue elegido a pesar de su oposición favorable al ingreso de España en OTAN, algo a lo que su partido se oponía agriamente. Pero la astuta inversión de Kissinger resultó rentable y González consiguió, en su momento, incorporar a España a la Alianza Atlántica a pesar de la oposición resuelta de su partido".
\end{abstract}

${ }^{23}$ M. GALLERO, Bárcenas. La caja fuerte, op. cit., pág. 110 
americanos $^{24}$. Financiar campañas de partidos como estrategia anticomunista fue, por otra parte, una práctica habitual en la política exterior secreta de Estados Unidos, especialmente en países occidentales con partidos comunistas fuertes como Italia ${ }^{25}$. El PCE, por su parte, recibía financiación de la Unión Soviética sujeta a los vaivenes de la relación del partido con Moscú, y además había puesto en marcha durante la clandestinidad un curioso sistema de financiación basado en las comisiones a través de empresas que comerciaban con países del bloque del Este ${ }^{26}$. El peculiar modelo de financiación de la UCD tuvo incluso el cualificado apoyo de Juan Carlos de Borbón, que en 1977 envió una carta al Sha de Persia, realizando un interesante repaso a las prácticas financieras de los partidos en la época, y solicitando una ayuda de 10 millones de dólares para financiar la reestructuración y consolidación de la coalición centrista, y la creación de un partido político para Suarez que pudiera servir de "soporte a la monarquía y a la estabilidad de España"27.

La Ley de Asociaciones Políticas de 1976 prohibía y sancionaba "toda recepción de fondos procedentes del extranjero o de Entidades o personas extranjeras", por lo que todas estas prácticas se realizaron durante la transición política, obviamente, primero desde la clandestinidad $y$, una vez legalizados los partidos, luego desde la ilegalidad. La escuetísima Ley de Partidos de 1978, sin embargo, derogó esa prohibición (junto con el resto de obligaciones contables y de control económico que recogía la Ley de Asociaciones Políticas), que volvió en las posteriores leyes de

\footnotetext{
24 J. VERSTRYNGE, Memorias de un maldito, Grijalbo, 1999, pp. 206-207: "No había que ser hipócritas ¡todos habíamos recibido ayudas! Si AP las había recibido de la Fundación Hans Seidel, y la UCD lo había hecho de la Konrad Adenauer, era ilusorio pensar que el PSOE iba a ser una excepción en relación con la Friedrich Ebert. Es más, imagino que, al igual que AP, que inundaba a la Hans Seidel de falsas facturas, el PSOE y la UCD habrían ordenado abundantemente a sus respectivos patrocinadores, el SPD y CDU. Por mi parte, al igual que por parte de los tesoreros de AP, mostraba una elevada imaginación a la hora de sacarle marcos a los alemanes para AP. Y lo digo sin rubor: éstos actuaban como procónsules de Washington, destinados a aplicar las directrices del imperio en la península ibérica y Latinoamérica. Pues peor para ellos ja pagar!".

${ }^{25}$ J. E. MILLER, "Taking off the gloves: The United States and the Italian elections of 1948". Diplomatic History, n. 1 v. 7,1983

${ }^{26}$ F. HERNÁNDEZ SÁNCHEZ, "Comerciando con el diablo. Las relaciones comerciales con el Telón de Acero y la financiación del PCE a comienzos de los años 60", Comunicación presentada en el VI Congreso de la Asociación de Historiadores del Presente La apertura internacional de España. Entre el franquismo y la democracia, 2014
}

${ }^{27}$ G. MORÁN, Adolfo Suárez: ambición y destino. Debate Editorial, 2009, pp. 166-167 
financiación de partidos, limitada a la prohibición de la financiación pública extranjera. La participación financiera internacional en las formaciones políticas españolas, al menos la de gobiernos y aliados extranjeros, se redujo probablemente a partir de finales de los años $70^{28}$ y una vez decaída la preocupación por el posible éxito electoral del PCE, resurgiendo como problema con el escándalo Flick, en los ochenta, y durante episodios como el de la mencionada financiación de Siemens al partido socialista. Aunque parecía convertida en una problemática relativamente menor, la cuestión ha cobrado más recientemente un nuevo auge al hilo de las acusaciones vertidas contra uno de los partidos emergentes del nuevo sistema político español post-crisis, Podemos, y la supuesta recepción de fondos provenientes de Venezuela. A raíz probablemente de ello, y pese a las muchas otras (y probablemente prioritarias) lagunas que tapar, el legislador tuvo a bien, de hecho, introducir en 2015 en el Código Penal como delito agravado la financiación por parte de Gobiernos y organismos, entidades o empresas públicas extranjeras o de empresas relacionadas directa 0 indirectamente con los mismos.

\section{El capitalismo nativo}

Donde la efervescencia de los años setenta y ochenta como un "far west" de la financiación de partidos, donde todo valía, deja sin duda el legado de una cultura que pervive en la actualidad, es en la relación con el mundo empresarial. La excepcional alegalidad de este periodo no tiene, en realidad, nada de excepcional, y está obviamente vinculada al desarrollo del capitalismo durante la época. Otros países sufrieron procesos similares, de los cuales el ejemplo italiano es quizás el más paradigmático. Caciagli, que estudió también el caso español ${ }^{29}$, contextualiza de manera breve y contundente el surgimiento de tangentopoli de la siguiente manera:

"Una explicación de carácter intrínseco al sistema político y económico italiano es la degeneración tanto de la función empresarial como de la función de regulación del Estado en los años ochenta. Las reglas del mercado fueron

\footnotetext{
${ }^{28}$ P. DEL CASTILLO, "Problems in Spanish party financing", en H. ALEXANDER y R SHIRATORI, (eds.) Comparative political finance among the democracies, Westview Press, 1994

29 M. CACIAGLI, Elecciones y partidos en la transición española. Centro de Investigaciones Sociológicas, 1986
} 
sacrificadas al interés dominante de grupos privados y de grupos políticos. Las grandes obras públicas (estadios de fútbol, hospitales, autopistas, líneas de ferrocarril, reconversiones de grandes áreas industriales, nueva urbanización después de desastres naturales, etc.) ofrecieron oportunidades de enlace entre políticos y empresarios. El mismo capitalismo italiano acentuó su componente financiera: la mutación postindustrial aumentó la importancia del dinero" ${ }^{30}$.

Sin duda el contexto en España es paralelo. Distintos autores ${ }^{31}$ han resaltado un aspecto fundamental y a la vez olvidado a la hora de analizar la problemática de la financiación de partidos: a cada modelo financiero de partido corresponde un modelo organizativo de partido. Si, a partir de esa premisa, tenemos en cuenta el contexto de fuerte desregularización que tanto en materia financiera como en materia organizativa que los propios partidos produjeron y disfrutaron hasta muy recientemente, podemos simplificar la cuestión de a qué modelo tendieron los partidos españoles desde la transición acudiendo a una figura utilizada por distintos analistas: la de "partido empresa" ${ }^{32}$, como una suerte de evolución del partido catch-all. Se trata de un partido fuertemente jerarquizado, con una intensa concentración de poder en una élite de administrados y dirigentes, emancipado de las lógicas de militancia de base propias del partido de masas, y muy dependiente en cambio de su habilidad en la captación legal e ilegal de fondos y de la explotación de los recursos a los que la política institucional permite tener acceso. Como cualquier modelo ideal de partido, ninguno de las formaciones españolas responde de manera esquemática a ese modelo (que tiene su mejor ejemplo en Forza Italia de Berlusconi) y por el contrario, son distintos los modelos de organización/financiación que coexisten en los distintos partidos políticos analizados individualmente.

30 M. CACIAGLI, Clientelismo, corrupción y criminalidad organizada. Centro de Estudios Constitucionales, 1996, pp. 97-98

31 J. HOPKIN, "The problem with party finance: Theoretical perspectives on the funding of party politics", Party politics, n. 6 v. 10, 2004; M. MAROTO CALATAYUD, La financiación ilegal de partidos políticos, op. cit.

${ }^{32}$ L. FERRAJOLI, "El Estado constitucional de Derecho hoy: el modelo y su divergencia de la realidad" en P. ANDRÉS IBAÑEZ (ed), Corrupción y Estado de Derecho. El papel de la Jurisdicción, Trotta, 1996; J. HOPKIN, y C. PAOLUCCI, "The business firm model of party organisation: Cases from Spain and Italy", European journal of political research, n. 3 v. 35, 1999; E. RODRÍGUEZ, La política en el ocaso de la clase media. El ciclo 15M-Podemos, Traficantes de Sueños, 2016 
La empresarización organizativa y financiera de los partidos españoles prácticamente desde su surgimiento en los años 70 es un proceso fácilmente constatable. La propia UCD era conocida entre sus líderes como "la empresa", como bien rememora Morán ${ }^{33}$, resaltando cómo la palabra "partido" y todo lo que ella implicaba era poco grata a las élites reformistas del franquismo y a la amalgama ideológica que formaba la coalición. Luis Bárcenas, convertido hoy en una suerte de símbolo vivo de las prácticas de financiación ilegal varias décadas, llegó al partido en 1982, de hecho, según sus palabras, por una "pura cuestión mercantil. Pasé de cobrar 30.000 pesetas al mes a un sueldo mucho más alto. Me afilié al partido porque no me quedó otro remedio. Verstrynge nos iba reclutando, arrinconándonos, mientras nos decía ‘CCómo que no estás todavía afiliado?’”34. Bárcenas se integró en el partido, de hecho, cuando se incorporó en bloque al grupo de gestores de las empresas del exbanquero y primigenio conseguidor Ángel Sanchis (utilizadas para financiar a Alianza Popular), como encargados de las cuentas de la formación política. Se trataba del llamado "clan de Badajoz", uno de los varios grupos en la política de clanes del Partido Popular, peculiar forma de articular la democracia interna en una formación que prohíbe las corrientes de opinión ${ }^{35}$.

El recurso a empresas vinculadas más o menos directamente a los partidos, bien para financiarlos directamente a partir de actividades económicas reales, o bien como sociedades pantallas destinadas a canalizar contribuciones y donaciones, normalmente con origen en dinero público proveniente de concesiones y licencias, ha sido una constante para todas las formaciones políticas, conocida y amparada por la tolerancia del negocio en común ${ }^{36}$. La lista de empresas que han financiado legal e ilegalmente a los partidos españoles cubre buena parte del espectro económico nacional. La propia CEOE financió a los partidos conservadores durante la transición y

\footnotetext{
${ }^{33}$ G. MORÁN, Adolfo Suárez: ambición y destino, op. cit.

${ }^{34}$ M. GALLERO, Bárcenas. La caja fuerte, op. cit., pág. 99

${ }^{35}$ G. SÁNCHEZ MEDERO, "Tramas y clanes en el Partido Popular". El Viejo Topo, n. 56, 2009.

${ }^{36}$ Un ejemplo entre muchos posibles: cuando a raíz de una posible adjudicación a Dragados y Construcciones y de un contrato de limpieza de Alicante, que no llegó a concretarse, Roberto Naseiro y Salvador Palop comentaban cómo, si la compañía quería algo, "que pasen por el camino, y luego se abre la puerta de Valencia" (M. GALLERO, Bárcenas. La caja fuerte, op. cit., pág. 141); la comisión era el $2 \%$ para el Partido Popular y el $1,5 \%$ para el PSOE.
} 
los años ochenta, a través de fórmulas de todo tipo, incluido el giro de cuotas patronales extraordinarias a las grandes empresas, actuando la asociación patronal como "cámara de compensación" ${ }^{37}$. Curiosamente sabemos, gracias a los sumarios de Filesa o Gürtel, más sobre la financiación ilegal que sobre la legal, sobre la cual el Tribunal de Cuentas ha mantenido, desde el comienzo de su labor fiscalizadora hasta la reciente prohibición de las contribuciones empresariales, un estricto secreto ${ }^{38}$. Las prácticas de financiación empresarial oculta que hoy se debaten a raíz de la publicación de los papeles de Bárcenas sobre la caja B del Partido Popular han sido también una constante en la democracia española. Las compañías eléctricas financiaron generosamente a UCD y luego a AP, ante la amenaza de que los socialistas cumplieran en 1982 su programa y nacionalizaran el sector eléctrico ${ }^{39}$. En los sumarios de Filesa se revelaron las contribuciones de $B C H$, BBV, ABB Energía, Pryca, Focsa, Catalana de Gast, Camunsa CEAM, Kidiqag, Abengoa, CEPSA, Elsan y Enasa. En los papeles de Bárcenas aparecen registrados pagos de sociedades como Mercadona, Construcciones Hispánica, OHL, Grupo Sando, Sacyr Vallehermoso, Azvi, FCC o Construcciones Rubau. De entre ellos podemos destacar dos grupos de actividad: las constructoras y los bancos.

\section{Las constructoras}

Las empresas constructoras, como sector pujante de la burbuja española, han tenido efectivamente un papel de especial relevancia. Como afirmaba en los años noventa Pradera ${ }^{40}$, sin que la situación haya cambiado particularmente: "la sospecha de que los constructores y los promotores urbanísticos intercambian favores políticoadministrativos de los ayuntamientos, a cambio de contribuir a la financiación oculta de los partidos cuyos representantes toman esas decisiones, está presente en muchos de

\footnotetext{
${ }^{37}$ C. DÁVILA y L. HERRERO, De Fraga a Fraga, op. cit. pág. 109

${ }^{38}$ Sobre los problemas y evolución de la función fiscalizadora del Tribunal de Cuentas sobre los partidos políticos, ver L. DELGADO DEL RINCÓN, "El control económico-financiero de los partidos políticos por el tribunal de cuentas: su potestad sancionadora". Revista de Derecho Político, 97, 2016; E. PAJARES MONTOLÍO, "La financiación de los partidos políticos". EUNOMÍA. Revista en Cultura de la Legalidad, n. 11,2016

${ }^{39}$ C. DÁVILA y L. HERRERO, De Fraga a Fraga, op. cit. pág. 106

${ }^{40}$ J. PRADERA, Corrupción y política... op. cit., pág. 71
} 
los casos de corrupción surgidos en estos años, sean cuales sean las siglas de la formación que ocupa el poder". Los efectos de esa interacción entre corrupción y desarrollo urbanístico son, literalmente, tangibles y visibles en todo el país. Como señalan los ingenieros de caminos y arquitectos responsables del proyecto "Nación Rotonda" ${ }^{41}$, que mapea visualmente la evolución del urbanismo de pueblos, polígonos industriales, puertos o autovías desde el año 2000, es fácil rastrear la corrupción siguiendo la estela del desarrollo urbanístico desaforado de los últimos años. Existe "una alta correlación entre los pueblos en los que se descubre un caso de corrupción, sea urbanística o no, y las entradas de Nacionrotonda. Casi cada vez que sale un caso nuevo en un pueblo nosotros ya lo teníamos en la web"42. Uno de los problemas de fondo es, efectivamente, la financiación de los ayuntamientos: "la única manera que tenían de financiarse era estos desarrollos [...] la capacidad de recaudar de las corporaciones municipales se limita a unos pocos impuestos (basuras, IBI, etc.). Sin embargo, por cada desarrollo urbanístico nuevo al Ayuntamiento de turno le corresponde, además de los terrenos considerados dotaciones públicas, el $10 \%$ de los terrenos con aprovechamiento lucrativo (aproximadamente, según la región), más los correspondientes impuestos, puestos de trabajo, etc. [...] Si además hay una legislación urbanística sobredesarrollada, se abren las puertas a la corrupción"43.

La vinculación entre corrupción, legislación y política urbanística, y con ella los tremendos efectos económicos y sociales de la burbuja inmobiliaria, ha sido señalada repetidamente y de manera relativamente temprana ${ }^{44}$. Lamentablemente, lo evidente

\footnotetext{
41 Recuperado de http://www.nacionrotonda.com. Otro proyecto similar e igual de interesante, "Cadáveres Inmobiliarios" (http://cadaveresinmobiliarios.org), documenta "las consecuencias que han sufrido el paisaje y el territorio en España con la crisis económica y el fracaso del modelo urbano desarrollista."

42 Eldiario.es, Radiografía (desde el cielo) de 15 años de urbanismo descontrolado, eldiario.es, 21/06/2014, recuperado de http://www.eldiario.es/sociedad/Radiografia-anosurbanismo-descontrolado 0 272973168.html (último acceso 28/11/2017)

${ }^{43}$ Ibídem.
}

${ }^{44}$ A. GÓMEZ-CÉSPEDES, A. M. PRIETO DEL PINO y P. STANGELAND, "Urbanismo, corrupción y delincuencia organizada: Un proyecto de la Costa del Sol”, Boletín Criminológico, n. 65, 2003; J. L. DíEZ RIPOLLÉS y A. GÓMEZ-CÉSPEDES, A., "La corrupción urbanística: Estrategias de análisis", Anuario de la Facultad de Derecho de la Universidad Autónoma de Madrid, n. 85, 2008; F. JIMÉNEZ SÁNCHEZ, "Boom urbanístico y corrupción política en España", Mediterráneo económico, n. 14, 2008; L. M. JEREZ DARIAS, V. O. MARTÍN MARTÍN y R. PÉREZ GONZÁLEZ, "Aproximación a una geografía de la 
del problema no ha motivado una adecuada intervención pública y legislativa. Es evidente que las jugosas oportunidades de financiación que estas operaciones especulativas abren no solo para ayuntamientos sino para partidos políticos, han tenido mucho que ver con esa inacción.

Uno de los ejemplos más flagrantes de la connivencia entre el urbanismo, la corrupción, y la actividad de los partidos políticos, surgió a la luz a raíz del caso Gürtel: uno de los imputados, apoderado de la constructora Rubau, afirmó ante el juez instructor pertenecer a una "Comisión de Infraestructuras" del Partido Popular, en la que también participaban, entre otros, el extesorero del PP Álvaro Lapuerta, y Manuel Nuñez, que fue presidente del Tribunal de Cuentas entre 2007 y 2012, y podría haber compatibilizado ambas labores. En palabras de uno de los abogados querellantes en el caso Bárcenas ${ }^{45}$.

"La Comisión de Infraestructuras del PP -que no aparece en los estatutos de este partido- compuesta por empresarios de constructoras y políticos además del tesorero, elaboraba las infraestructuras a realizar de manera previa a las elecciones (...) Lo más grave -sinceramente- de los papeles de Bárcenas es que muestran cómo las grandes empresas de infraestructuras cooptaron los consejos de ministros para que hicieran las políticas que ellas diseñaban a través de la Comisión de Infraestructuras del PP. Esto les costó muy poco dinero en comparación con el enorme daño causado al interés general"

Evidentemente esa comisión no consta en el organigrama del partido y habría funcionado al margen de cualquier control interno y supervisión orgánica. Esto plantea un problema fundamental que ya hemos apuntado con anterioridad: el del tipo de organización idónea para albergar y favorecer prácticas de financiación ilegal y de corrupción como estas. Como afirma Pradera "la autonomización de los partidos respecto a sus electores y a la sociedad en su conjunto pone en marcha un proceso de oligarquización, jerarquización y disciplina interna, favorecedor entre otras cosas de medidas necesariamente secretas para la financiación ilegal de la organización. La pescadilla se muerde la cola: una estructura oligárquica idónea para obtención irregular

corrupción urbanística en España", Ería, n. 87, 2012; G. ROGER FERNÁNDEZ, "Urbanismo y corrupción: Etiología de una práctica ilícita", Encuentros Multidisciplinares n. 50, 2015

${ }^{45}$ F. A. KLINK, “Veinte años (1993-2013) de 'política hidrológica' en España: El secuestro de la política pública”, Revista de Economía Crítica, n. 17, 2014: 39 
de recursos refuerza y consolida los poderes de la cúpula para mantener bien guardados los secretos inconfesables" ${ }^{46}$.

\section{Los bancos}

La influencia de las entidades bancarias sobre las formaciones políticas españolas se ha popularizado como motivo de protesta desde el 15M. Hasta el punto en que algunos de los nuevos partidos tras el ciclo de movilización 2011-14, y en particular Podemos, han hecho gala de prohibir estatutariamente esa forma de financiación ${ }^{47}$.

Es difícil sobreestimar el papel de la banca en la financiación de los partidos españoles. Ya hemos mencionado la cuantía del endeudamiento de los partidos españoles en el ejercicio 2013. Aunque las distintas leyes de financiación de partidos han puesto tímidos límites al endeudamiento bancario, esta ha sido la forma más habitual de obtener recursos legales junto con la financiación pública. Según el informe del Tribunal de Cuentas relativo al año 2011, once partidos estaban, de hecho, en quiebra técnica. Los saldos patrimoniales negativos de UDC (11,2 millones de euros), CiU (10,1 millones), IU (8,5 millones), BNG (3,4 millones). Izquierda Unida de Andalucía (3,2 millones), ICV (3,1 millones); Izquierda Unida de la Comunidad de Madrid (1,8 millones), el Bloc Nacionalista Valenciá (1,1 millones), Chunta Aragonesista (614.000 euros) UPyD (581.000); Partido Aragonés (545.000 euros) y Amaiur (439.000 euros) son alarmantes a la luz de lo que históricamente han sido los efectos del endeudamiento sobre las formaciones políticas.

Desde los orígenes del sistema español de partidos, las grandes formaciones han acumulado deudas millonarias, con implicaciones políticas de primer orden. Según

\footnotetext{
${ }^{46}$ J. PRADERA, Corrupción y política... op. cit., pág. 164

${ }^{47}$ Lo que ha dado lugar a formas innovadoras de endeudamiento, como los microcréditos, que no por ser más democráticas han sido del todo bien recibidas por los partidos tradicionales (ver S. GONZÁLEZ y M. MAROTO, "La financiación participativa en partidos como herramienta de cambio político", eldiario.es, 10/05/2015, recuperado de: http://www.eldiario.es/zonacritica/financiacion-participativapartidos-herramienta-politico 6 385371492.html; Eldiario.es, "El PP duda de la legalidad de la financiación de Podemos", eldiario.es, 10/4/2015, recuperado de: http://www.eldiario.es/clm/PP-dudalegalidad-financiacion-Podemos 0 375862910.html, último acceso 28/11/2017).
} 
Dávila y Herrero, por ejemplo, "el apoyo parlamentario de AP a UCD le costó al entonces partido gubernamental no menos de 1000 millones de pesetas, los que debían los seguidores de Fraga ${ }^{48}$. La desaparición de la propia UCD tuvo mucho que ver con su situación financiera, hasta el punto en que fue un representante de la CEOE quien aconsejaría a los dirigentes de la formación "lo mejor es que cerréis, que cerréis el partido. Porque, si no, tendremos que ejecutar la deuda"49. La CEOE, que había financiado a UCD y luego a AP, podía, gracias a la presión financiera, proponer directamente programas y estrategias políticas ${ }^{50}$ o imponer candidatos ${ }^{51}$. Dirigentes del PSOE justificaron la creación del holding de empresas en torno a Filesa en la necesidad de hacer frente a las enormes deudas contraídas en el referéndum de la OTAN de 1986, para el que no se contó con financiación pública ${ }^{52}$; tampoco el cambio de posición del partido respecto a la entrada en la alianza atlántica estuvo libre de sospechas en cuanto a estar influenciada por las donaciones recibidas por Alemania y EE UU ${ }^{53}$. En definitiva, la posibilidad de condonar la deuda (una práctica habitual que no fue considerada equivalente a una donación hasta la Ley de Financiación de Partidos de 2007 y finalmente prohibida en 2015), de financiar a otras formaciones políticas, o de promover otras nuevas que sirvieran de competencia política (piénsese

\footnotetext{
${ }^{48}$ C. DÁVILA y L. HERRERO, De Fraga a Fraga, op. cit. pág. 106

${ }^{49}$ Ibídem.

${ }^{50}$ C. DÁVILA y L. HERRERO, De Fraga a Fraga, op. cit. pp. 94 y ss.

${ }^{51}$ M. GALLERO, Bárcenas. La caja fuerte, op. cit., pág. 105
}

52 "El partido tuvo que hacer una campaña electoral muy diferente y con un coste desorbitado de unos 600 millones que dispararía el endeudamiento hasta los años noventa, inaugurando métodos irregulares de financiación a través de sociedades mercantiles para compensarlo. De hecho, el presupuesto federal del PSOE para 1985 había multiplicado por diez el manejado en 1978, alcanzando los 2.014 millones, de los que 1.835 eran subvenciones estatales, pero con una carga de deuda enorme porque, ya con anterioridad al referéndum, se reservaban 533 millones para la amortización de la deuda, sin contar la que manejaban, sobre todo, por su lado socialistas catalanes y vascos". (A. MATEOS LÓPEZ, "Los socialistas españoles y la cuestión atlántica hasta el referéndum de 1986", Ayer: Revista de Historia Contemporánea, n. 3 v. 103, 2016: 68-69)

${ }^{53}$ Según Mateos, sin embargo, "no está claro que el principal apoyo exterior financiero del PSOE en los primeros momentos de la transición, la socialdemocracia alemana, y su antiguo líder Willy Brandt, ahora presidente de la Internacional Socialista, ejercieran una presión directa en el viraje atlantista, dado que éste se emprendió ya con los socialistas españoles en el poder y el SPD alemán se había posicionado ya en la oposición contra los euromisiles. Más bien, González y Brandt compartieron la dirección de una activa, por entonces, Internacional Socialista que trataba de promover la distensión y se había implicado en la cuestión centroamericana con posiciones diferenciadas a las de Estados Unidos.", A. MATEOS LÓPEZ, “Los socialistas españoles...", op. cit., p. 56. 
en la fallida Operación Roca), dieron a la banca y a las cajas de ahorro (que constituyen un punto central del entramado de influencia de los partidos ${ }^{54}$ ) desde el principio una enorme capacidad de influencia sobre el comportamiento de las organizaciones políticas. En algunos casos el control financiero de los partidos por parte de la banca ha sido casi literal: fue por ejemplo un gerente del Banco Santander "enviado por Emilio Botín" (que de paso le regaló a Fraga un coche blindado) quien "organizó las finanzas de Alianza Popular", con el objetivo de "poner orden en el partido y, sobre todo, para conocer dónde terminaban los donativos que entregaba el banquero" ${ }^{\mathrm{N} 5}$.

Aunque las distintas leyes de financiación de partidos han puesto tímidos límites al endeudamiento bancario, esta ha sido la forma más habitual de obtener recursos legales junto con la financiación pública. Pese a las limitaciones impuestas a la condonación en 1987 y 2007, la cancelación de deudas por parte de las entidades bancarias se ha perpetuado entre las grandes formaciones durante todos los años de democracia. Como subraya Ariño ${ }^{56}$, el Tribunal de Cuentas en su informe sobre el año 2002 cifró las condonaciones habidas entre 1993 y 2002 en 25,4 millones de euros; entre 1990 y 2002, en 26,1 millones; una media anual de condonaciones por importe de 400 millones de pesetas/año. EI PSOE y PSC habrían logrado ver condonados, por parte de la Caixa, BBK o Santander, desde 2004 a 2009, 40 millones de euros; ERC se habría beneficiado de una condonación de 2,7 millones por parte de la Caixa; EI PP, de 2,6 millones por parte de Caixa Galicia en 1996. De estas entidades dependía, en definitiva, cuánto se debía y por tanto cuánto se tenía. Hasta que 2015, como hemos señalado ya, se prohíben las condonaciones bancarias, la situación no distaba mucho de la que reflejaba a mediados de los años ochenta una conversación entre Fraga y

\footnotetext{
${ }^{54}$ Ver R. JUSTE DE ANCOS, La formación del bloque de poder económico en España: consejeros, capital y estado en el ibex35. Tesis Doctoral. Universidad Complutense de Madrid, 2016.

${ }^{55}$ M. GALLERO, Bárcenas. La caja fuerte, op. cit., pp. 105-106.

${ }^{56}$ G. ARIÑO ORTIZ, La financiación de los partidos políticos, Documentos del Foro de la Sociedad Civil n. 1, 2009
} 
Ángel Sanchís: a la pregunta de Fraga “¿Cuánto se debe?”, Sanchís contestó "Depende de lo que se pague" ${ }^{57}$.

\section{La respuesta legislativa y política}

Para concluir este repaso por la financiación de partidos en España, no podemos dejar de hacer una referencia a la historia de la ilegalidad de la financiación; es decir, a la reacción legislativa a estas prácticas por parte de sus principales actores protagonistas, los partidos.

Los partidos han explotado estratégicamente su doble faceta privada y pública para mantener y proteger sus arraigadas dinámicas de financiación, desde su posición de monopolio del poder legislativo ${ }^{58}$. Pese a presentarse como concesiones a la transparencia y el control y como respuesta a los sucesivos escándalos, las sucesivas reformas han ido aumentando la provisión de fondos a las formaciones políticas sin servir para limitar el recurso a la financiación ilegal. La primera Ley de Financiación de Partidos de 1987 fue interpretada por muchos, más como una respuesta a los escándalos de los años ochenta, como una necesidad imperiosa ante el nivel de deuda acumulado por las formaciones políticas: se consolidaba el modelo de financiación pública, mientras que se dejaban abiertas obvias lagunas que imposibilitaban el control efectivo de los límites que se imponían a la privada. Entre ellas, las más llamativas, eran la posibilidad de realizar donaciones anónimas (lo que permitía fraccionar las donaciones sin que el Tribunal de Cuentas pudiera detectar irregularidad alguna), y la ausencia de un régimen sancionador que permitiera al Tribunal de Cuentas imponer multas o sanciones. Pese a la flagrancia del problema, ambas cuestiones no se resolvieron hasta veinte años después, con la reforma de 2007. Pese a ello, el Tribunal de Cuentas, un órgano de escasos recursos e independencia para asumir eficazmente la función de fiscalizar los partidos, no ha llegado a imponer más que un par de

\footnotetext{
${ }^{57}$ C. DÁVILA y L. HERRERO, De Fraga a Fraga, op. cit. pág. 116

${ }^{58}$ Ver G. MARTíNEZ COUSINOU, El control de la corrupción política en el ámbito de la financiación de Ios partidos políticos: actores, intereses y estrategias en España y Reino Unido. Tesis doctoral. UNED, 2013
} 
sanciones a partidos en todos estos años ${ }^{59}$. La peculiar ambivalencia del legislador tuvo otro de sus momentos álgidos en la reforma de la ley en 2012: presentada como destinada a reducir la cantidad de dinero público destinado a los partidos, a la vez, de manera casi oculta, eliminó las restricciones a las donaciones a las fundaciones políticas que incluía la ley de 2007. El problema de las fundaciones políticas no ha sido resuelto en la reforma de 2015, y constituye una forma evidente de evadir los nuevos límites y requisitos de la legislación en vigor.

La reforma del sistema de financiación de partidos en 2015 fue, sin embargo, peculiar, probablemente por responder a un contexto político inédito en los cuarenta años de democracia: la transformación del sistema de partidos hacia un sistema no bipartidista, y el surgimiento de nuevos partidos que enarbolan una cultura organizativa distinta y que articulan electoralmente el fuerte sentimiento contra la corrupción. Entre las principales novedades de la reforma podemos resaltar dos: la prohibición de las donaciones por parte de personas jurídicas, y la introducción en el Código Penal de un delito de financiación irregular de partidos ${ }^{60}$. Ninguna de las dos parece precisamente una solución definitiva al problema de la financiación ilegal. Por una parte, las donaciones legales realizadas por empresas y personas jurídicas siempre han sido un porcentaje pequeño, y fácilmente prescindible, de la financiación de las formaciones políticas españolas. Por otra, la redacción del tipo penal deja fuera numerosas prácticas de financiación irregular, no es aplicable a las fundaciones políticas, y no tiene visos de ser de fácil aplicación por parte de los tribunales ${ }^{61}$.

Si decimos que la reforma del 2015 fue peculiar no es solo porque se acudiera a la muy largamente postergada criminalización de la financiación ilegal, lo que denota la inédita intensidad de la presión por aparentar firmeza frente a la corrupción. Lo es

\footnotetext{
${ }^{59}$ L. DELGADO DEL RINCÓN, “El control económico-financiero de los partidos políticos...”, op. cit.

${ }^{60}$ No deja de ser llamativo cómo durante décadas se ha hablado en los medios de comunicación españoles, de manera casi normalizada, del "delito de financiación irregular", cuando hasta 2015 tal delito no existía como tal, y ni siquiera estaba en vigor un régimen sancionador administrativo eficaz para ese tipo de prácticas. Los tribunales penales tenían que enfrentarse a los casos de financiación ilegal aplicando otros delitos recogidos en el Código Penal: cohecho, tráfico de influencias, delito fiscal, apropiación indebida, etc.

${ }^{61}$ M. MAROTO CALATAYUD, "Financiación ilegal de partidos políticos", en G. QUINTERO OLIVARES (dir.), Comentario a la reforma penal de 2015, Tirant Lo Blanch, 2015
} 
también porque, por vía de la regulación penal, se introducen en la Ley de Partidos Políticos y en la Ley de Financiación de Partidos Políticos algunas nuevas disposiciones de control interno, que hacen recaer las funciones de fiscalización en los propios partidos, bajo amenaza de responsabilidad penal. Ante la ausencia de una regulación directa de la democracia interna y la responsabilidad política en los partidos, se introducen por esta vía algunas interesantes obligaciones de control orgánico. Pese a su escaso alcance, es en la interacción entre democracia interna, responsabilidad política y responsabilidad penal donde la reforma resulta más interesante y novedosa con respecto al pasado.

Precisamente el controvertido papel de la jurisdicción penal en el control de las prácticas de financiación ilegal es uno de los puntos clave para entender lo ocurrido en todos estos años. El argumento de la controversia es el siguiente: de manera algo contraintuitiva, la responsabilidad penal ha sido instrumentalizada por los partidos políticos para desertizar el campo de la responsabilidad política. En la habitual estrategia defensiva de las élites partidistas, todo lo que no fuera objeto de condena firme por un tribunal penal era una práctica lícita de financiación, que no merecía sanciones o medidas en otro ámbito, ni siquiera el político $u$ orgánico. Las garantías del proceso penal, en particular la presunción de inocencia, debían ser aplicables también a todo escándalo relativo al dinero en política: la democracia interna que consagra el artículo 6 de la Constitución quedaba, en último término, supeditada a los largos y complejos procesos penales. "Todo político se hallaba a salvo de cualquier crítica mientras una sentencia firme de los tribunales no lo declarase culpable de un delito incluido en el Código Penal”62.

Salir del histórico impasse en materia de financiación ilegal de partidos exige, entre otras cosas, empezar a distinguir las esferas de la responsabilidad política y la responsabilidad penal ${ }^{63}$. La confusión entre ambas esferas no solo ha permitido la desertización de la responsabilidad política en el sistema español de partidos: ha empobrecido hasta límites inaceptables el debate sobre la financiación de partidos. En

\footnotetext{
62 J. PRADERA, Corrupción y política... op. cit., pág. 74

${ }^{63}$ M. DÍAZ Y GARCÍA CONLLEDO, "Responsabilidad penal y responsabilidad política: la necesidad de no confundir", Transjus working paper 2/2014, 2014
} 
efecto, la discusión sobre la financiación de partidos ha quedado en buena parte limitada al control y la prevención de la financiación ilegal, obviándose casi totalmente todas las cuestiones que tienen que ver con cómo distintos modelos de financiación afectan al funcionamiento y organización de los partidos, y a la democracia misma. En España no ha habido un debate mínimamente articulado sobre los criterios que han de tenerse en cuenta para considerar legales y adecuadas unas formas de financiación e ilegales y perniciosas otras; tampoco, en general, sobre qué modelo de partidos políticos queremos.

\section{Conclusiones}

En este aspecto, sin embargo, también la sociedad y la política va por delante de las instituciones. La transformación de la cultura política que ha tenido lugar en España a partir del $15 \mathrm{M}$, si bien opera sobre todo en un ámbito ajeno a la política institucional, se ha traducido también en un cambio sin precedentes en el sistema de partidos nacido de la transición política. En los últimos años hemos asistido al surgimiento de nuevas formaciones políticas que se mueven en un camino intermedio e incierto entre el ímpetu de formas radicalmente nuevas de organización y de cultura militante, y las viejas rutinas partidarias de siempre. Si los cuarenta años de experiencia en materia de financiación ilegal de partidos han pasado fundamentalmente por alto la vinculación entre dinero, funcionamiento partidista y democracia interna, los nuevos partidos, al menos en su momento de emergencia, han sido un motor de innovación organizativa y cultural. Podemos, por ejemplo, dio una refrescante importancia en sus inicios a la publicación detallada de cuentas, la democratización de la financiación, la independencia de los órganos disciplinarios internos, y la participación de los militantes. Aunque las perspectivas de ese primer impulso no parecen particularmente buenas, sino que más bien parece languidecer frente a los ataques de una cierta lógica reactiva ${ }^{64}$, algunos cambios han llegado aquí para quedarse.

${ }^{64}$ En el momento de terminar de redactar este artículo, la ejecutiva de Podemos vivía una fuerte confrontación con sus propios órganos disciplinarios, con motivo de una reforma estatutaria que no había sido aprobada por la Asamblea General (Ver Elpais.com, "La mayoría de las comisiones de garantías de Podemos declaran nulos los nuevos estatutos", Elpais.com, 31/08/2017, recuperado de: 
El poder monolítico de las élites de los partidos (a veces reducidas hasta el ridículo al llamado "triángulo del poder": presidente, secretario general y tesorero ${ }^{65}$ ) para formar las listas electorales y tomar todas las decisiones de relevancia parece haber quedado herido con la rápida popularización de las elecciones primarias y las consultas a la militancia que, con todos los problemas que puedan plantear, sirven de límite a las tendencias oligarquizantes. Partidos como PSOE y Ciudadanos ya han propuesto vincular la financiación de los partidos a su democracia interna ${ }^{66}$, un paso fundamental, extraño a la cultura partidista de la transición, para afrontar de manera seria la cuestión de la corrupción ${ }^{67}$. Por tímidos que sean, estos cambios, sumados a la introducción de algunas medidas legales, ya mencionadas, destinadas a resucitar del mundo de las fantasmagorías la esfera de la responsabilidad política, permiten por lo menos albergar esperanza en que el incierto presente desemboque en una nueva cultura política donde las formaciones partidistas no se vean recompensadas por mantener estructuras basadas en el secreto, el clientelismo, el funcionamiento antidemocrático, y el alejamiento de sus bases y de la sociedad en su conjunto. Las próximas reformas en materia de partidos, sin duda por venir, quizás no sean ya solo sobre financiación ilegal y quizás resulten más interesantes que las anteriores.

https://politica.elpais.com/politica/2017/08/31/actualidad/1504197869 683669.html (último acceso 28/11/2017) Resulta toda una novedad que los órganos disciplinarios de un partido español se enfrenten abierta y públicamente a los dirigentes de la organización. Sin duda ello tiene que ver con la elección a través de primarias de los miembros de esos órganos, y con su regulación estatutaria como órganos independientes, pese a que esta, en el caso de Podemos, fue severamente limitada en el último congreso.

${ }^{65}$ M. GALLERO, Bárcenas. La caja fuerte, op. cit., pág. 102

${ }^{66}$ Lavanguardia.com, "PSOE y C's vinculan la financiación a los partidos a su democracia interna", lavanguardia.com, 24/02/2016, recuperado de

http://www.lavanguardia.com/politica/20160224/302399158496/psoe-y-c-s-vinculan-la-financiacion-a-lospartidos-a-su-democracia-interna.html (último acceso 28/11/2017)

${ }^{67}$ Sobre sistemas de indicadores para evaluar el funcionamiento interno en partidos políticos, ver por ejemplo la propuesta de S. DE LA ROA VERDUGO, "La asignatura pendiente (y menos sexy de los partidos políticos): la organización", Revista Internacional de Pensamiento Político, n. 11. v. II, 2016. 